\title{
Impact of county-scale land use change on the value of ecosystem services: A case study in Nanping, Fujian,China
}

\author{
LiLi Zhao $^{1}$ \\ ${ }^{1}$ College of Urban and Rural Construction, Shaoyang University, Shaoyang, 422000, China
}

\begin{abstract}
With the changing behavior of land use by explosive population growth, the ecological environment is constantly disturbed and destroyed by humans, and the value of ecosystem services is obviously degraded. After the introduction of the national new-type urbanization plan, counties have become the key areas to promote new-type urbanization, and county land use is exceptionally active. Therefore, it is especially urgent to grasp the impact of county land use changes on ecosystem service values. Based on remote sensing satellite image interpretation to obtain county land use classification data, the changes of ecosystem service values in County between 1995 and 2015 were thoroughly explored. The research results show that the total value of ecosystem services has increased in most regions during the 20 years, among which, the service value of Shunchang County has increased most significantly. In terms of the service values of different land use types in each region, woodland is the main contributor to ecological services in different regions. From different time periods, Jian'ou City had the highest value of woodland ecosystem services in 1995 and 2015. In contrast, Songxi County had a lower value of services for each ecosystem type during 20 years.
\end{abstract}

\section{Introduction}

Land use has an integrated function of ecology, production and living (referred to as "triple life") [1], which transforms land with natural properties into an artificial ecosystem with social properties. Land use type is a complex of natural or artificial land cover that can change in form and state [2]. Humans live in ecosystems, receiving gifts from them every moment and releasing harmful substances to them, which in serious cases lead to disruption of ecosystems and eventually affect human survival and development [3]. Land use change will not only cause changes in the environment on which human beings depend, thus affecting the structure and function of the earth's biosphere, chemosphere and physical sphere, but also cause imbalance in the material and energy flows of the ecosystem, resulting in a drastic reduction of biodiversity and global warming [4]. Land use is one of the closest intersections between human and nature, and land use change and ecosystem service function change are a pair of contradictory unities that develop synergistically [5-8]. Therefore, it is important to study the value of ecosystem services under land use change for the conservation of regional ecosystem service functions.

In recent years, against the background of rapid urban expansion, the urbanization process of counties has accelerated significantly, causing environmental disasters such as continuous decrease of biodiversity and increase of heat island effect intensity in counties with weak awareness of ecological and environmental protection. For example, Li et al. [9] used the urban ecotourism zone as an empirical evidence, used the urban ecotourism area as the empirical object to determine the degree of land use fragmentation through the landscape pattern index, and then explored the evolutionary characteristics of land use and ecosystem service values, and revealed the influence mechanism of land use fragmentation on ecosystem service values; Feng et al. [10] studied the national key ecological function area (Hanzhong City) found that woodland, cultivated land and watershed were the main contributors to ecological services in Hanzhong city and sensitive factors to changes in ecological service values. The findings of the existing studies show that the research on the impact of land use change on ecosystem service values has been relatively mature, but the empirical evidence objects are mostly gathered at large and medium scales, and the empirical analysis on the county scale is still rare. Therefore, Nanping City, the largest prefecturelevel city in Fujian Province and one of the earliest developed areas in Fujian Province, was selected as the study area, and 10 districts (cities and counties) under its jurisdiction were taken as specific research objects. Using two phases of remote sensing image data in 1995 and 2015, based on software platforms such as ENVI and ArcGIS, the modified ecosystem value per unit area equivalent factor method was applied to study the impact of land use changes on ecosystem service values in different regions of Nanping City, with a view to providing technical support for ecosystem protection and ecological civilization construction in Nanping County and Fujian Province. 


\section{Overview of the study area}

This paper takes the districts (cities and counties) under Nanping City, Fujian Province as the study case. Nanping City is located in the northern part of Fujian Province, commonly known as northern Fujian, with a land area of $2.63 \times 10^{4} \mathrm{~km}^{2}$. Nanping City has two municipal districts, five counties and three county-level cities, including Yanping District, Jianyang District, Shunchang County, Pucheng County, Guangze County, Songxi County, Zhenghe County, Shaowu City, Wuyishan City and Jian'ou City (Figure 1). Nanping City belongs to the central subtropical temperate monsoon climate, with an annual average temperature of $17^{\circ} \mathrm{C} \sim 19^{\circ} \mathrm{C}$ and an annual average rainfall of $1684 \sim 1780 \mathrm{~mm}$, with distinct rainy seasons. Among the areas under the jurisdiction of Nanping, Shunchang County has the reputation of "the hometown of cedar wood in China", and Wuyishan City is one of the only four "World Natural and Cultural Heritage Sites" in China. The total household population at the end of 2019 was $318.26 \times 10^{4}$, with a resident population of $269 \times 10^{4}$ and an urbanization level of $57.5 \%$.

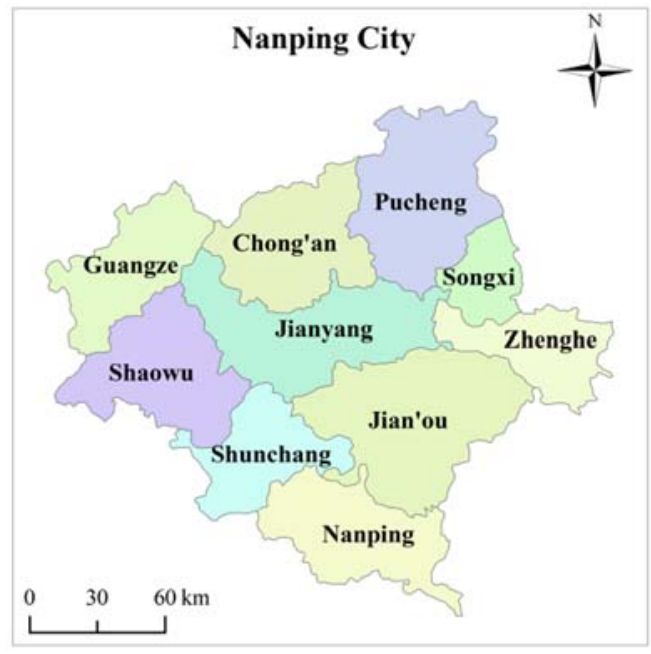

Fig. 1. Map of study area

\section{Research Methodology}

\subsection{Data sources}

According to the purpose and significance of the study, and considering factors such as data accessibility, the Landsat5 TM of Nanping City in 1995 and the Landsat-7 ETM of 2015 were obtained from the geospatial data cloud platform (http://www.gscloud.cn/), and the spatial resolution was $30 \mathrm{~m} \times 30 \mathrm{~m}$. With reference to China's land use classification system and combined with the geographical characteristics of Nanping City, this paper classifies the study area into six land use types: woodland, grassland, cultivated land, building land, water area and unused land. After previous experience and the need for research classification, it was found that the RGB combination of bands 5, 4 and 3 could more clearly distinguish the six land use types needed in this study. Therefore, the Layer stacking function in ENVI Classic was used to combine each remote sensing image map according to bands 5, 4 and 3. And then, the histogram matching method was used to mosaic the images, import the shp vector map of the study area, and execute the cropping operation for the final land use classification data.

\subsection{Research Methodology}

\subsubsection{Selection of ecosystem service indicators}

Drawing on the research results of Xie et al. [11] and referring to other related studies, this paper selected nine indicators of ecosystem services, including gas regulation, climate regulation, water conservation, soil formation and protection, waste treatment, biodiversity conservation, food production, supply of raw materials, and recreation and culture.

\subsubsection{Value per unit area of each ecosystem service}

Xie et al. [11] established a Chinese ecosystem service unit area value equivalent factor table, based on the research results of Costanza et al. and combined with the actual situation in China, which provides a reference for the calculation of the value of ecosystem services in China, and the equivalent factor table is widely used by Chinese scholars. According to the equivalence table developed by Xie et al. [11] with the land use types actually classified in this paper, the equivalence factor table of the unit area value of ecosystem services conforming to Nanping City was made, see Table 1 . It is necessary to explain that the construction land is not included in Table 1, because the ecosystem service is its functional utility, and its utility size refers to the degree of satisfying human needs, so only its positive utility to human is calculated in this paper. The construction land are mainly rural residential sites and urban industrial and mining sites, which damage the natural ecological environment and continuously discharge sewage, waste gas and solid waste into the environment, so they not only produce little positive ecological utility but also produce negative utility. Based on the above considerations, the ecosystem service value of construction land is not accounted for in this paper.

Table1. Equivalent value per unit area of terrestrial ecosystem services in Nanping City.

\begin{tabular}{|c|c|c|c|c|c|}
\hline Types & $\begin{array}{l}\text { Wood } \\
\text { land }\end{array}$ & $\begin{array}{c}\text { Cultiv } \\
\text { ated } \\
\text { land }\end{array}$ & $\begin{array}{c}\text { Water } \\
\text { area }\end{array}$ & $\begin{array}{c}\text { Unu } \\
\text { sed } \\
\text { land } \\
\end{array}$ & $\begin{array}{c}\text { Grass } \\
\text { land }\end{array}$ \\
\hline gas regulation & 3.50 & 0.50 & 0.00 & 0.00 & 0.80 \\
\hline $\begin{array}{l}\text { climate } \\
\text { regulation }\end{array}$ & 2.70 & 0.89 & 0.46 & 0.00 & 0.90 \\
\hline $\begin{array}{c}\text { water } \\
\text { conservation }\end{array}$ & 3.20 & 0.60 & 20.38 & 0.03 & 0.80 \\
\hline $\begin{array}{l}\text { soil formation } \\
\text { and protection }\end{array}$ & 3.90 & 1.46 & 0.01 & 0.02 & 1.31 \\
\hline waste treatment & 1.31 & 1.64 & 18.18 & 0.01 & 1.95 \\
\hline $\begin{array}{l}\text { biodiversity } \\
\text { conservation }\end{array}$ & 3.26 & 0.71 & 2.49 & 0.34 & 1.09 \\
\hline food production & 0.10 & 1.00 & 0.10 & 0.01 & 0.30 \\
\hline $\begin{array}{l}\text { supply of raw } \\
\text { materials }\end{array}$ & 2.60 & 0.10 & 0.01 & 0.00 & 0.05 \\
\hline $\begin{array}{l}\text { recreation and } \\
\text { culture }\end{array}$ & 1.28 & 0.01 & 4.34 & 0.01 & 0.04 \\
\hline
\end{tabular}


The ecosystem service unit area value equivalents are all based on the unit area value of food production services of farmland ecosystems. Therefore, the unit area value of farmland ecosystems food production services is first calculated with the following equation.

$$
E_{a}=\frac{1}{7} \cdot T_{a} \cdot T_{b}
$$

Where $E_{a}$ denotes the unit area value of farmland ecosystem services (yuan $/ \mathrm{hm}^{2}$ ). $T_{a}$ represents the average baseline grain yield in the study area $\left(\mathrm{kg} / \mathrm{hm}^{2}\right)$. $T_{b}$ is the national average grain price (yuan $/ \mathrm{kg}$ ).

The value per unit area of other ecosystem services in Nanping City is obtained from Equation 2 and Table 1. The formula is as follows.

$$
C V_{i j}=E_{a} \cdot f_{i j}
$$

Where $C V_{i j}$ represents the first $i$ land use type $j$ value per unit area of ecosystem services (yuan $/ \mathrm{hm}^{2}$ year). $f_{i j}$ represents the $i$ land use type $j$ equivalent factor of the value of the ecosystem service of the species. $E_{a}$ sames as above.

\subsubsection{Total value of ecosystem services}

The total value of ecosystem services was calculated for different regions, using the following equation.

$$
E S V=\sum_{i=1}^{n} \sum_{j}^{m} A_{i} \times C V_{i j}
$$

Where $E S V$ is the total value of ecosystem services, and $A_{i}$ is the total value of the first $i$ area of the land use type, and $C V_{i j}$ is the area of the $i$ land use type $j$ is the unit area value of the first ecosystem service.

\section{Results and Analysis}

\subsection{Total value of ecosystem services in the county}

From Figure 2, it can be found that overall most regions have higher total value of ecosystem services in 2015 than in 1995, among which, Shunchang County has the most obvious increase, from 14.872 billion yuan in 1995 to 18.637 billion yuan in 2015 , with a total increase of 3.765 billion yuan in 20 years, indicating that compared with other regions, overall Shunchang County has the most improved ecological environment in 20 years. From different time period, Jian'ou City has higher total value of ecosystem services than other regions in 1995 and 2015, which is related to the largest area of Jian'ou City. Similarly, the total value of ecosystem services in Songxi County is the smallest in all time periods, mainly because of the smallest area of Songxi County.

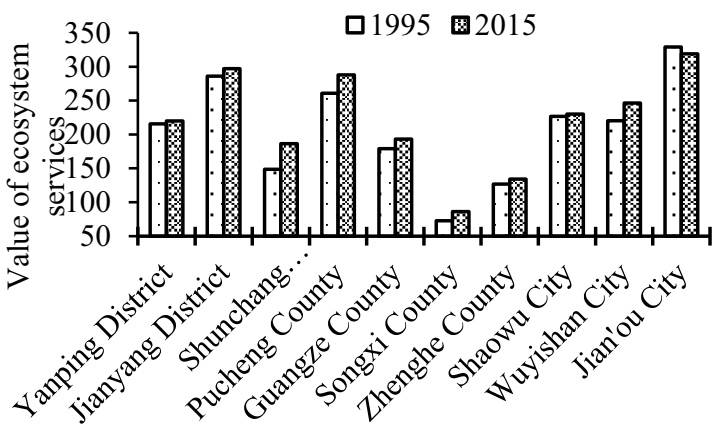

Fig. 2. Total value of ecosystem services in different regions from 1995 to 2015 (Billion Yuan)

\subsection{Service values of different ecosystems in the county}

In 1995, the change of county ecosystem service value is shown in Figure 3. Among all regions, woodland ecosystem service value is the highest compared with other ecosystem types because all woodland covers the largest area. In contrast, the ecosystem service value of woodland in Jian'ou City is the largest, at 303.66 billion yuan, while Jianyang District and Pucheng County are the second, at 249.91 and 231.03 billion yuan, respectively. Among water ecosystems, the ecosystem service value of Yanping District is the highest, at 61.24 billion yuan, while Jianyang District is the second, at 23.52 billion yuan. The ecosystem service value of cultivated land in Pucheng County is slightly higher than that of other regions, with 11.97 billion yuan, while the service value of cultivated land in Yanping District is the lowest, with only 2.60 billion yuan.

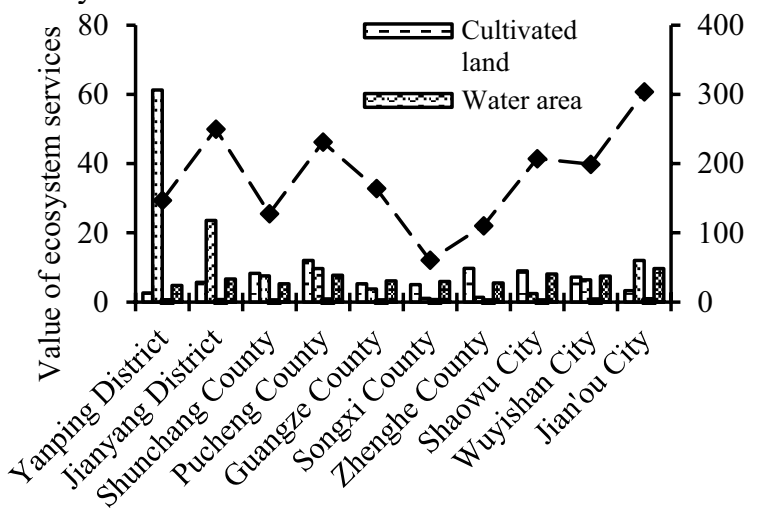

Fig. 3. Value of ecosystem services in different regions in 1995 (Billion Yuan)

From Figure 4, it is found that the value of woodland ecosystem services increased slightly in most regions in 2015 , and the order of the value of woodland services in each region was: Jian'ou City (289.18 billion yuan) > Jianyang District (282.95 billion yuan) $>$ Pucheng County (258.05 billion yuan) $>$ Wuyishan City (231.19 billion yuan) $>$ Shaowu City (214.09 billion yuan) $>$ Yanping District (19.455 billion yuan) ) $>$ Glossy County (17.517 billion yuan) $>$ Shunchang County ( 155.58 billion yuan $)>$ Zhenghe County (114.17 billion yuan) $>$ Songxi County (78.67 billion yuan). The value of Water ecosystem services fluctuates greatly, with Shunchang County, 
Yanping District and Pucheng County having a higher value of water ecosystem services of 26.36, 19.04 and 19.03 billion yuan, respectively. The value of cultivated land ecosystem services did not change much except Jian'ou City. At the same time, it is worth noting that the value of grass ecosystem services in Jian'ou City decreased significantly in 2015, and the value of ecosystem services was only 2.85 billion yuan, which is mainly due to the fact that $35.52 \%$ of the grassland shifted to cultivated land in 20 years in Jian'ou City.

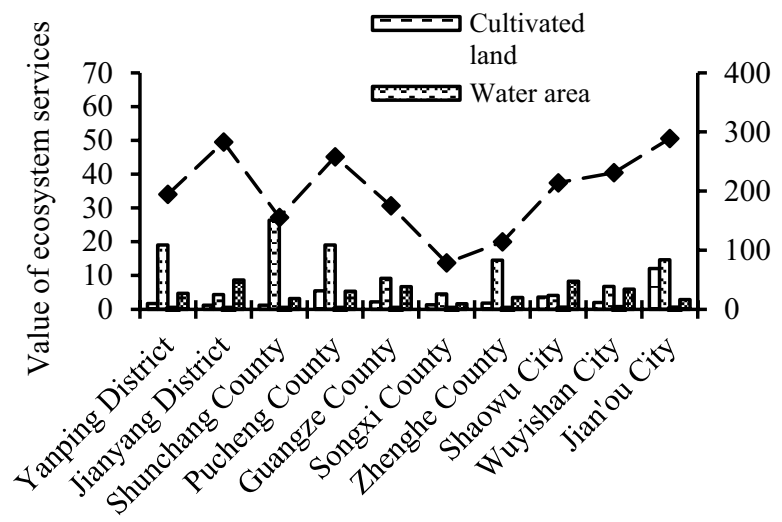

Fig. 4. Value of ecosystem services in different regions in 2005 (Billion Yuan)

\section{Conclusion}

The study was based on the remote sensing interpretation data of land use in Nanping City in two periods of 1995 and 2015, and slightly modified on the basis of the Chinese ecosystem service unit area value equivalent factor table established by Xie et al. [11] to make an ecosystem service unit area value equivalent factor table in line with Nanping City, and quantitatively explored the impact of land use change on ecosystem service value in Nanping County. The conclusions are as follows.

(1) In terms of different regions, the total value of services increased to different degrees in most regions in 2015, among which, the value of services increased the most significantly in Shunchang County, with a total increase of 37.66 billion yuan in 20 years.

(2) In terms of the changes in ecosystem service values of different land use types in different regions, since woodland and unused land are the largest and smallest among the land use types in each region, respectively, the ecosystem service values of woodland and unused land are also the highest and lowest in each region.

(3) From different time periods, compared with other regions, the highest value of woodland ecosystem services was in Jian'ou City in 1995 and 2015. It is noteworthy that the value of services of all ecosystem types in Songxi County was lower in 20 years, which is related to the smallest area of Songxi County among the regions.

\section{Acknowledgments}

This work was supported by the Education Department of
Hunan Province (No.19C1670), and the Specialized Research Fund for the Doctoral Program of Shaoyang University (No. 17ZX03).

\section{References}

1. W.Y. Dai, F.Q. Jiang, W.L. Huang, L.H. Liao, K. Jiang.Study on the transformation of land use function and ecological service value based on "three living spaces"--Take Fuzhou New District as an example.Journal of Natural Resources,2018,33(12): 2098-2109.

2. P.J. Shi, J. Chen, Y. Pan. Analysis of land use change mechanism in Shenzhen[J].Journal of Geography,2000(02):151-160.

3. C.H. Wu, P.J. Du, K. Tan. Study on land cover and landscape pattern changes in coal mining areas[J].Journal of Coal,2012,37(06):1026-1033.

4. J.G. Canadell, W.L. Steffen, P.S. White.IGBP/ GCTE terrestrial transects: Dynamics of terrestrial ecosystems under environmental change[J].Journal of vegetation science. 2002,13(3):298-300.

5. C.Y. Ouyang, R.S. Wang. Ecosystem service function, ecological value and sustainable development $[\mathrm{J}]$.World Science and Technology Research and Development,2000(05):45-50.

6. M. Li. Causes and countermeasures of frequent environmental damage in China:A perspective of inter-regional environmental competition[J].Finance and Trade Economy,2009(09):82-88.

7. H.H. Wu, L.Y. Zhao, S.Z.Li.Impact of land use change on ecosystem service value in Huainan City based on GEE[J]. Ecological Economics,2021,37(02): 146-152.

8. F. Li, X.Y. Zhang, H.L. Guo. Spatial and temporal variation characteristics of ecosystem service values in the Three Gorges reservoir area in the past 30 years based on land use[J].Soil and Water Conservation Research,2021,28(02):309-318.

9. D.J. Li , L. Yang, Y.H. Yu, W.B. Luo, Z.F. Wang. The impact of land use fragmentation on ecosystem service value in urban ecotourism areas--Wuhan East Lake Ecotourism Area as an example[J]. Journal of Ecology,2019,39(13):4782-4792.

10. J.M. Feng, L.X. Guo, X.H. Li. Spatial and temporal changes in land use in Hanzhong City and its impact on the value of ecosystem services[J].Soil and water conservation research,2020,27(01):275-282.

11. G.D. Xie, C.X. Lu, Y.F. Leng, D. Zheng, S.C. Li. Valuation of ecological assets on the Qinghai-Tibet Plateau[J].Journal of Natural Resources,2003(02): 189-196. 